\title{
Against essential mental normativity again
}

\author{
ASBJØRN STEGLICH-PETERSEN Aarhus University
}

Forthcoming in a special issue of Dialogue: Canadian Review of Philosophy on normativity, edited by Christine Tappolet and Alain Voizard.

ABSTRACT: In a recent paper (2008), I presented two arguments against the thesis that intentional states are essentially normative. In this paper, I defend those arguments from two recent responses, one from Nick Zangwill in his (2010), and one from Daniel Laurier in the present volume, and offer improvements of my arguments in light of Laurier's criticism.

RÉSUMÉ: Dans un article récent (2008), j’ai présenté deux arguments contre la thèse selon laquelle les états intentionnels sont essentiellement normatifs. Dans cet article, je défends ces arguments contre deux critiques récentes, l'une de Nick Zangwill publiée en 2010 et l'autre de Daniel Laurier dans le présent volume; de plus, je révise mon argument à la lumière des objections de Laurier.

\section{Essential mental normativity}

It is a popular view among philosophers of mind that mental states, particularly intentional states and propositional attitudes ${ }^{1}$, are constitutively or essentially governed by normative principles, such that any adequate account of these states and attitudes must refer to such normative principles. There are many variations of this view on the market. It came into prominence in the modern literature primarily 
through the work of Donald Davidson $(1980,1984)$ and Saul Kripke (1982), the latter of which attributes a version of the view to Ludwig Wittgenstein (1953). Some of it's current defenders, most notably Robert Brandom (1994), attribute versions of the thesis to philosophers as far back as Kant and Hegel. The currently most prominent defenders of the thesis, which I shall from now onwards refer to as "normative essentialism", include, among others, Ralph Wedgwood (2007, 2009), Nick Zangwill (1998, 2005a, 2010), Paul Boghossian (2003), Alan Millar (2004), and Nishi Shah (2003).

Although a number of different positive arguments have been presented in favor of the thesis, most of them are variations over a single theme: attributing intentional states, or the capacity for having intentional states, presupposes or entails judgments about the rationality, or capacity for rationality, of the agent to whom the states are attributed. For example, Davidson $(1980,1984)$ has argued that in interpreting another agent as having some particular set of intentional states, such as beliefs and desires, we are forced to presuppose that the agent in question on the whole is rational with respect to the relations between her intentional states, and correct with respect to individual intentional states, since we only on that assumption will be able to infer her intentional states from her overt behavior and interaction with her environment (Davidson refers to this as the "principle of charity"). Kripke (1982) has argued that no non-normative property, such as dispositions stated in purely descriptive terms, could be the property in virtue of which an agent instantiates some intentional state, since no such property allows us to understand how agents can think and act in ways that are mistaken given the relevant intentional state. More recently, Wedgwood (2007) has argued that intentional states, understood as certain dispositions, can be specified only in normative terms, since the dispositions by virtue 
of which one can be in the relevant intentional states are dispositions to do and think what the relevant attitude makes rational or correct. Normativists conclude from observations such as these, that intentional states must be essentially normative.

As Zangwill points out in (2010), the view that intentional states are essentially normative has important and far-reaching metaphysical consequences in the philosophy of mind and beyond. According to Zangwill, it favors a weak rather than a strong realism about intentional states; it makes expressivism about normative claims impossible; and it makes eliminativism about intentional states self-refuting. These consequences are in addition to the usual obstacles a normative theory of mind would present to any naturalist aspirations in the area. All of this makes an evaluation of the claim all the more important.

\section{Against essential mental normativity}

In my (2008), I presented two distinct arguments against normative essentialism. Both arguments start from the observation that any version of normative essentialism which makes it a priori that the relevant propositional attitudes are governed by certain normative principles, such that having any of those attitudes makes one subject to such normative principles, will be committed to regarding attributions of propositional attitudes as normative judgments. For example, if it is part of a specific version of normative essentialism about belief that believing $p$ is correct if and only if $p$ is true, and knowledge of this principle is a priori for anyone competent with the concept of belief, then this version of normative essentialism will be committed to the claim that attributions of beliefs involve a normative judgment to the effect that the subject of the belief falls under this normative principle. Both arguments also assumed what I, following Zangwill (2005b), called the "Because Constraint". This 
states that it is an a priori requirement on normative judgments, that whenever someone makes a normative judgment, he or she must be prepared to provide a nonnormative judgment in support of it, at least if challenged to do so. The idea behind this principle is that we always regard normative properties as obtaining in virtue or because of certain non-normative properties. If someone attributed a normative property to something or someone, but denied that it has this property at least in part because of some non-normative property, we would be inclined to say that the attributor has misunderstood something about the nature of normative properties. The Because Constraint is not identical to, and doesn't follow from, the principle that normative properties weakly supervene on non-normative properties, but it does seem motivated to some extent by this principle. According to the principle of weak normative supervenience, normative properties are such that, necessarily, whenever some such property $\mathrm{F}$ is instantiated by $\mathrm{x}$, there is some non-normative property $\mathrm{G}$ such that $\mathrm{x}$ is $\mathrm{G}$ and for any $\mathrm{y}$, if $\mathrm{y}$ is $\mathrm{G}$ then $\mathrm{y}$ is $\mathrm{F}$. Normative supervenience is thus by itself silent on whether normative properties obtain "because of" non-normative properties, and it is equally silent on any obligation we may have to point out the nonnormative properties we regard as sufficient for the normative properties we ascribe when making normative judgments. Yet these further commitments do seem plausible, and they are at least motivated by normative supervenience in the sense that they wouldn't be plausible at all in the absence of normative supervenience (Cf. Laurier's discussion of the Because Constraint in this volume).

Given this, the first argument against normative essentialism (named “Argument $A$ " in my original presentation) can be summarized as follows. If propositional attitudes were essentially norm constituted, and this were knowable $a$ priori, then propositional attitude ascriptions would be normative judgments. If this 
were so, the Because Constraint would impose a requirement on such ascriptions that a non-normative judgment is made in their support. But there is no such requirement for propositional attitude ascriptions; we do not have to back up propositional attitude ascriptions with non-normative, or, indeed, non-mental judgments; so propositional attitudes are not essentially norm constituted.

My second argument (named "Argument $B$ " in my original presentation) is that if propositional attitudes were essentially norm constituted, and this were knowable a priori, propositional attitude ascriptions would be normative judgments, in which case they could not act as non-normative support for normative rationality judgments in a way that satisfies the Because Constraint. But propositional attitude ascriptions can act as such support. For example, when judging it irrational for $S$ to believe that $p$, it clearly suffices as non-normative support to judge that $S$ believes some other proposition inconsistent with $p$. So propositional attitudes are not essentially norm constituted. ${ }^{2}$

It appears, however, that my arguments have failed to convince defenders of normative essentialism that the thesis is false. In the next sections, I defend the above arguments from two recent responses, one from Nick Zangwill in his (2010), and one from Daniel Laurier in the present volume, and offer some improvements of my arguments in light of Laurier's perceptive criticism.

\section{Reply to Zangwill}

In order to appreciate Nick Zangwill's reply, it is necessary to give a little more detail about his particular brand of normative essentialism. Normative essentialism about propositional attitudes is defined by Zangwill $(2005 \mathrm{a}, 2010)$ as the view that certain normative properties are essential for propositional attitudes to be the kind of 
propositional attitudes they are. The normative properties Zangwill has in mind are the properties of being subject to certain norms of rationality. In short, it is essential to any given propositional attitude that it makes rational or irrational certain other propositional attitudes, and that it itself is made rational or irrational by other propositional attitudes. For example, it is essential to $S$ desiring that $p$ that it rationalizes or rationally requires $S$ intending that $p$; it is essential to $S$ believing that $p$ that it rationally requires that $S$ does not believe anything incompatible with $p$, etc.

It is tempting to agree with Zangwill that adopting what he calls "weak" rather than "strong" normative essentialism can help him solve the kind of difficulty pointed out by my arguments. Zangwill has previously defended the strong version (1998), but has now instead adopted the weak one (2005a, 2010). According to the strong version, propositional attitudes are or essentially have normative properties. This version is clearly vulnerable to both of my objections. On the weak version, however, propositional attitudes essentially have properties that, although themselves nonnormative, explain or necessitate the relevant normative properties. For example, although $S$ desiring that $p$ is itself a non-normative property, the property is essentially such that it explains or necessitates it being rational for $S$ to intend that $p$. This means that Zangwill can deny that propositional attitude ascriptions are normative judgments, thus enabling him to avoid commitment to the implausible claim that propositional attitude ascriptions must be backed by some non-normative judgment, and to maintain that propositional attitude ascriptions can serve as the nonnormative backing of normative rationality judgments.

As I argued in my (2008), however, the weak version of normative essentialism faces a dilemma concerning the exact nature of the necessitation of normative properties by propositional attitudes. The question is whether or not the 
necessitation must be knowable a priori to persons competent with the concepts of the relevant propositional attitudes. If they were not knowable a priori, normative essentialism would loose its central appeal. Normative essentialism was meant to explain the rational requirements generated by propositional attitudes, but if these requirements were known only a posteriori, it could be rational for someone competent with propositional attitude concepts to rationally deny that having some propositional attitude gives rise to the relevant rational requirement, in which case it could hardly be called a rational requirement. On the other hand, if the dependence of normative properties upon non-normative propositional attitudes must be known $a$ priori to persons competent with the concepts of the relevant propositional attitudes, the normative essentialist must deny Hume's law, that one cannot deduce a normative judgment from a non-normative one..$^{3}$

In his response to this, Zangwill (2010) concedes that the "weak" normative essentialist has to accept that the necessitation must be $a$ priori, and thus accept that a normative judgment can be deduced from a non-normative one. He thinks, however, that we can allow an exception to Hume's law in this case. According to Zangwill, although Hume's law holds for normative moral judgments, it does not hold for normative rationality judgments. So while we cannot deduce a moral judgment from a non-normative judgment, we can, according to Zangwill, deduce a normative rationality judgment from a non-normative judgment. ${ }^{4}$ Zangwill cites a number of examples in support of this claim:

Consider these examples. A is angry at $\mathrm{X}$. A does not believe that $\mathrm{X}$ has done anything wrong to A. If we know these, we can deduce that A is irrational - a normative property. Or consider: A wills end $\mathrm{X}$ and believes that $\mathrm{Y}$ is a means to $\mathrm{X}$. From knowledge of these, we can deduce that A rationally ought to will $\mathrm{Y}$ and that $\mathrm{A}$ is irrational if he does not will $\mathrm{Y}$ (other things being equal). Or: A has perceptual experience as of the fact that $p$. From knowledge of 
that, we can deduce that it would be rational of A to form the belief that $p$ (other things being equal). These are all violations of Hume's law. (Zangwill 2010: 30)

Zangwill assumes that these are all examples of valid inferences. Although I think that there is room for doubt in regard to this assumption, I will grant it for our present purposes. However, even if we grant that these are indeed valid inferences, they can be interpreted in several ways. Zangwill interprets them as violations of Hume's law, i.e. as valid inferences from non-normative judgments to normative ones. But there is another possible interpretation of the inferences, again assuming that they are valid, namely as inferences from non-normative judgments to other nonnormative judgments, in which case they would not be counterexamples to Hume's law, but would rather, by taking Hume's law as an assumption, show that rationality judgments are non-normative. ${ }^{5}$ Given the possibility of this alternative interpretation of Zangwill's examples, the question becomes which hypothesis is more plausible, given the datum of the valid inferences: that Hume's law allows exceptions in the case of rationality judgments and rationality judgments are normative, or that Hume's law is exceptionless and rationality judgments are non-normative?

It is important to keep in mind that my arguments against normative essentialism do not rely on the normativity of rationality judgments. The second of the two arguments, which is the one Zangwill responds to, does invoke as a premise that rationality judgments are normative. But if rationality judgments are not normative, normative essentialism looses any independent appeal it may have had in the first place. After all, the normative property, which according to the normative essentialist makes propositional attitudes normative, is precisely the property of being subject to rational requirements. This means that it is open to me at this point in the dialectic to deny the normativity of rationality judgments. 
So which interpretation of Zangwill's examples of valid inferences from propositional attitude judgments to rationality judgments is the most plausible? Do the inferences show that Hume's law has exceptions, or do they show that rationality judgments are non-normative? Although I cannot here provide a full argument that the latter interpretation is the more plausible one, three considerations should at least suffice to saddle Zangwill with the burden of proof.

The first consideration is that, despite traditional opinion to the contrary, the normativity of rationality judgments is a genuinely open question in the current debate on the subject. To mention just a few highlights of this debate, Niko Kolodny (2005) argues that we have no reason to be rational, and suggests an error-theory to explain why it often seems as if rational requirements give us reasons. In short, rational requirements seem to provide us reasons, because they stem from beliefs about what we have reason to do. So whenever an agent is bound by some rational requirement, that agent will believe that he has reason to comply with the requirement. John Broome $(2005,2008)$, taking normativity in general to concern what we have reason to do, also professes not to be able to find a sense in which rational requirements give us reason to comply with them, and Andrew Reisner (2011) has recently argued for a similar conclusion in the case of theoretical rationality. A somewhat less radical option would be to interpret rational requirements and other putatively normative principles applying to intentional states as instrumental principles, expressing descriptive statements on how to satisfy one's ends. In previous work, I have defended such an account of the rational requirements and correctness conditions for belief (Steglich-Petersen 2006, 2009, 2011). On this account, believing some proposition $p$ is constitutively associated with an aim of believing $p$ truly. Correctness conditions for belief can then be interpreted as 
conditions for success or aim-satisfaction, and rational requirements for belief can be interpreted as instrumental principles stating how to ensure success for belief, which means that both correctness conditions and rational requirements turn out to be nonnormative, or at least not normative in any problematic sense, since instrumental principles and recommendations do not fall under Hume's law (Cf. Hare 1952). Of course, none of these alternative accounts of the analytic inferences suggested by Zangwill establishes that rationality judgments are non-normative. But it does mean that the normativity of rationality judgments cannot be assumed without argument. ${ }^{6}$

The second consideration is that nothing in the usual arguments in favor of Hume's law distinguishes between different types of normative judgments. The standard arguments typically establish more general theses, for example that no imperative conclusion can be validly inferred from a set of premises, which does not contain at least one imperative, or that no conclusion concerning what ought to be done, or what is good or valuable can be inferred from premises containing no such statement (see e.g. Hare 1952). But it is difficult to see what it could mean for rationality judgments to be "normative", if not, in the very least, one of these general things; if rationality judgments do not make imperative statements concerning what ought to be the case, what there is reason to do, or what is valuable, it is difficult to see what it could mean for them to be "normative". So if Zangwill wishes to accept Hume's law for moral normative judgments on the basis of the standard arguments for Hume's law, it is not clear why he should not be committed to accepting that insofar as rationality judgments are normative, Hume's law must govern those as well. But in that case, Hume's law forces upon Zangwill the dilemma of either accepting that propositional attitude judgments are normative, in which case he falls prey to my first argument, or denying that rationality judgments are normative after all, which 
removes any independent appeal normative essentialism may have had in the first place.

The third consideration is of a methodological nature. I take it to be a sound methodological principle that if it is a highly confirmed law that all Fs are G, and we encounter an $\mathrm{x}$ which is apparently $\mathrm{F}$ but not $\mathrm{G}$, then we have prima facie reason to doubt that $\mathrm{x}$ is really an $\mathrm{F}$, despite appearances. We thus have reason to provide support in favor of $\mathrm{x}$ being $\mathrm{F}$ before discarding the law - a reason that goes beyond whatever reason we normally have to make sure that $\mathrm{x}$ is $\mathrm{F}$ before judging this to be so. Quite plausibly, in such cases, our reasons for judging $\mathrm{x}$ to be F should include some explanation of why $\mathrm{x}$ is not $\mathrm{G}$, given that all other Fs are $\mathrm{G}$. For example, if it is a highly confirmed law that all ravens are black, and we encounter a bird that is apparently a raven, but not black, we have prima facie reason to doubt that the bird is really a raven, and thus have reason to provide evidence in favor of the bird being a raven, and to explain why it could be a raven without being black, before discarding the law that all ravens are black.

In the present case this means that since it is a highly confirmed law that all normative judgments are such that they cannot be deduced from non-normative ones, and it seems as if judgments about the rationality of a person can be deduced from non-normative judgments about propositional attitudes, this gives prima facie reason to doubt that judgments about the rationality of a person really are normative. We thus need to provide support for that claim before we can give up Hume's law. As a part of this, we should also provide some explanation of why normative rationality judgments can be deduced from non-normative judgments, when all other normative judgments cannot. So for us to accept Zangwill's examples as counterexamples to Hume's law, he must provide some independent support for thinking that rationality judgments 
really are normative, and some explanation for why they are exempt from Hume's law despite of this. Zangwill has provided neither, and as indicated above, the recent debate on the subject suggests that it will be very difficult for Zangwill to do so.

To conclude, although this may be insufficient to convince anyone with a prior conviction that rationality judgments are normative, it should be enough to shift the burden of proof. Zangwill cannot simply rely on the intuition that rationality judgments are normative in his purported counterexamples to Hume's law, but must provide some independent reason to regard them as normative. Until he has done so, we can consider his reply to my arguments ineffective.

\section{Reply to Laurier}

In his contribution to this volume, Daniel Laurier seeks to defend what he calls "intentional normativism" against a number of problems raised by the widespread assumption that the normative supervenes on the non-normative. Laurier's intentional normativism cannot simply be equated with normative essentialism about intentional states, such as the thesis defended by Zangwill, since Laurier rejects the "essentialist" component of the position as part of his defense of a normative theory of intentional states. Laurier instead defends a conceptual version of the thesis, according to which concepts of intentional states are normative without this implying a corresponding view of the properties that they designate. Laurier's version of the theory thus has the advantage of avoiding various problems there may arise for it stemming from the supervenience of normative properties upon non-normative properties. His discussion of these matters is not directly relevant to the evaluation of my arguments, however, so I shall abstain from rehearsing it here. 
Laurier's rejection of the essentialist component has implications for the original statement of my arguments against normativism, since the first premise of both arguments states that attributions of intentional states are normative judgments insofar as the attributed states have normative essences. However, since Laurier accepts that attributions of intentional states are normative judgments, independently of any motivation this claim might have had in normative essentialism, both of my arguments can be reconstructed in a way that simply takes this for granted. Since I too think that normative essentialism is false, I am obviously happy to accept the thus altered versions of my arguments offered by Laurier.

The alternative versions of my arguments thus both start from the premise stating the Because Constraint on normative judgments, i.e. that it is an a priori requirement on normative judgments that whenever $S$ makes a normative judgment, $S$ must be prepared to provide a non-normative judgment in support of it. After some consideration, Laurier accepts that this premise may actually be true, so I shall not here make any further attempt at justifying it. ${ }^{7}$

In Argument $A$, the target for Laurier's attack is the crucial premise 3 (originally premise 4), which, in the alternative version of the argument offered by Laurier, states that it is not an a priori requirement that whenever $S$ attributes some attitude, $S$ must be prepared to provide a non-normative judgment in support of it. In my original paper, I provided three arguments for this thesis, all of which Laurier rejects. My first argument was that the Because Constraint does not apply to attitude attributions because it is not a priori that mental attitudes supervene on non-mental, and thus non-normative, properties. Laurier rejects the relevance of this point on the basis of his prior rejection of the view that it is a priori that normative properties weakly supervene on non-normative properties. As mentioned earlier, evaluating 
Laurier's detailed argument for this rejection is beyond the scope of this paper, but fortunately, I think that the second and third arguments for premise 3 survive Laurier's criticism.

My second argument for premise 3 was that although we are often required to present non-mental, behavioral evidence to support our ascriptions of attitudes, such evidence could not plausibly be seen as non-normative grounding for normative judgments, and the general requirement to present evidence for one's empirical judgments should thus not be confused with the Because Constraint on normative judgments. Against this, Laurier complains that it is unclear whether I with this want to "deny that the requirement to be able to provide non-normative support for one's normative judgments is a requirement to be able to produce non-normative evidence for them" (2011), and goes on to say that he sees no reason to deny this. I agree that what I say here could perhaps be clearer, but I think that once suitably spelled out, my argument stands.

The argument here builds on the observation that the kind of non-normative grounding that we can be challenged to present for our normative judgments (call this "non-normative grounding"), is different in nature from the evidential grounding we can be challenged to present for any judgment of ours. These kinds of grounding are clearly not the same. This may be obscured by the fact that the two kinds of grounding do share some features. For example, both non-normative and evidential grounding will, if adequate, raise the probability of the grounded judgment being true, since trivially, by virtue of contributing to making true a normative judgment, nonnormative grounding for such a normative judgment also raises its probability. But non-normative grounding has several essential features, which evidential grounding doesn't have essentially. Perhaps most importantly, the facts, which can act as non- 
normative grounding of a normative judgment, will be facts in virtue of which the grounded normative judgment is true, and they will also help explain why the normative judgment holds. For example, the non-normative fact that a car has a fuelefficient engine may be cited as one of the facts in virtue of which it is a good car, and it also helps explain why it is a good car. Evidential grounding, by contrast, does not need to stand in either these relations to the grounded judgment, although it sometimes does, which makes the matters somewhat confusing. Evidence for a judgment does not need to consist of facts in virtue of which the judgment is true, and evidence does not need to stand in any explanatory relation to the content of the judgment to which it provides evidential support. For example, although a footprint on a beach is evidence that someone walked on it, it is not by virtue of the footprint that someone walked on the beach, and the footprint does nothing to explain why someone walked on the beach. So while normative grounding can always act as a kind of evidence for the normative judgment in question, there are instances of evidential grounding that cannot act as normative grounding.

This means that all I need for my argument to go through is that there are cases of attitude attributions that are sufficiently grounded, such that no further grounds of any kind is needed, by evidence, which does not also satisfy the conditions for normative grounding. And I think it should be evident enough that there are such cases. For example, it seems relatively uncontroversial that attitude attributions can be adequately grounded evidentially by reference to the behavior of the agent. But unless one adopts a strict behaviorist account mental attitudes, it would be strange to hold that it is in virtue of this behavior that the agent has the attitude, or that the behavior helps explain why the agent has the attitude, in which case reference to the behavior could not satisfy the Because Constraint. 
My third argument for premise 3 was that we often take purely mental manifestations such as assertions and first-person ascriptions as an entirely sufficient basis for ascribing intentional states, and it is not a conceptual requirement in such cases to hold that anything more is needed to ground the mental ascriptions made. Laurier agrees that attributions of intentional states may sometimes be sufficient as a basis for attributing other intentional states. But he claims that this fails to show that the Because Constraint doesn't apply to attributions of intentional states, since the Because Constraint allows that normative judgments may be appealed to in order to support other normative judgments, and the support that attributions of intentional states provides to other such attributions may therefore be of this normative kind.

Laurier is of course right when he observes that normative judgments occasionally, perhaps often, can be invoked to ground other normative judgments. As he points out, it seems reasonable, for example, to state the fact that we ought to let in some fresh air in favor of it being the case that we ought to open the window. He is also right that the Because Constraint is entirely compatible with this. All that principle states is that we always can be challenged to present non-normative grounds for our normative judgment. But this is entirely compatible with it sometimes being appropriate or even required to also present some further normative judgments in favor of the normative judgment to be grounded. Crucially, however, such additional normative grounds cannot be seen as sufficient to satisfy the Because Constraint. So insofar as Laurier accepts the Because Constraint on normative judgments, and accepts that attributions of intentional states are sometimes sufficient as support for other such ascriptions, he is forced to accept either that the Because Constraint doesn't apply to attributions of intentional states, or to deny that attributions of 
intentional states are normative. But either option is incompatible with Laurier's argument.

If the above characterization of the difference between non-normative grounding and evidential grounding, and further point about the insufficiency of normative grounding are adequate, the revisions to Argument $A$ needed to answer Laurier's criticism can thus be stated as follows:

\section{$\underline{\operatorname{Argument} A}$}

1. It is an a priori requirement on normative judgments that whenever $S$ makes a normative judgment, $S$ must be prepared to provide a non-normative judgment in support of it, which satisfy the conditions for non-normative grounding.

2. If attributions of attitudes are normative judgments, then it is an a priori requirement that whenever $S$ attributes some attitude, $S$ must be prepared to provide a non-normative judgment in support of it, which satisfy the conditions for non-normative grounding.

3. It is not an a priori requirement that whenever $S$ attributes some attitude, $S$ must be prepared to provide a non-normative judgment in support of it, which satisfy the conditions for non-normative grounding (evidential grounding which, does not satisfy those conditions, is sufficient).

Therefore,

4. Attributions of attitudes are not normative judgments.

Moving on to Laurier's discussion of my Argument $B$, the main focus of his attack is on premise 7 (originally premise 10), which, in the alternative version of the argument offered by Laurier, states that attributions of attitudes can act as support for 
judgments of rationality. Laurier claims that there are two possible readings of this premise, one of which is question-begging in the context, and the other of which is makes the premise insufficient to establish the conclusion. If the premise is taken to be that attitude ascriptions can act as non-normative support for judgments of rationality, he claims that it will make the argument question-begging, since, I take it, under that reading premise 7 alone would imply or even include the conclusion. On the other hand, if the premise merely is taken to be that attitude ascriptions can act as support for normative rationality judgments, without specifying what kind of support, the premises of the argument would fail to establish the conclusion, since it is compatible with wording that the kind of support invoked by the premise is different from that mentioned in the conclusion. I agree with Laurier as far as the original argument goes. As stated, the original argument is indeed question-begging. But there is an easy fix that will make the argument both valid and non-question-begging.

Note first that the Because Constraint, which figures as the first premise of both Argument $A$ and $B$ in the revised version (originally premises 2 and 7), states that, a priori, whenever we make a normative judgment, we can be demanded a nonnormative judgment in support of it. Given this, I only need to revise premise 7 (originally premise 10) to state that attributions of attitudes, at least sometimes, are sufficient as support for normative rationality judgment. That they are sufficient implies that there can be no requirement of further judgments in support of the rationality judgment, since this would contradict the sufficiency of the attitude attributions as support. But in that case, it follows, without begging the question, that attitude attributions can act as non-normative support of rationality judgments, since there would be cases where these attributions would be the only support needed for normative rationality judgments, and thus the only judgments needed to satisfy the 
Because Constraint. If Laurier wishes to maintain this objection, he must thus either reject the Because Constraint, or reject that attitude ascriptions, at least sometimes, are entirely sufficient as support for normative rationality judgments. Either option seems unattractive, and Laurier himself explicitly accepts both theses.

Given this, the revisions to Argument $B$ needed to answer Laurier's criticism can be stated as follows:

\section{$\underline{\operatorname{Argument} B}$}

1. It is an a priori requirement on normative judgments that whenever $S$ makes a normative judgment, $S$ must be prepared to provide a non-normative judgment in support of it.

5. Judgments of rationality are normative.

6. It is an a priori requirement that whenever $S$ makes a judgment of rationality, $S$ must be prepared to provide a non-normative judgment in support of it.

7. Attributions of attitudes are, at least sometimes, sufficient as support for rationality judgments, such that no other support of any kind is required.

Therefore,

4. Attributions of attitudes are not normative judgments.

Although I am grateful for the improvements prompted by them, I conclude that Laurier's objections to both Argument $A$ and $B$ are can be successfully met.

\footnotetext{
${ }^{1}$ For the purposes of this paper, the difference between intentional states and propositional attitudes is not of importance, and I shall use the terms interchangeably to fit the use of the authors under discussion.

2 See my (2008) for further details on these arguments.

${ }^{3}$ For further details, see Steglich-Petersen (2008).
} 


\footnotetext{
${ }^{4}$ In a footnote, Zangwill also draws attention to the more traditional counterexamples to Hume's law, due to Arthur Prior (1960). As Zangwill acknowledges, however, few are convinced by these examples. For a penetrating recent critique, see Gillian Russell (2010).

${ }^{5}$ For a parallel move concerning the truth norm for the correctness of beliefs, see Allan Gibbard (2005: 138-9).

${ }^{6}$ Further discussions casting doubt on the normativity of rationality can be found in Schroeder (2003) and in Glüer and Wikforss (2009).

${ }^{7}$ Among other things, Laurier discusses the degree to which the Because Constraint is motivated by weak normative supervenience, and says that while it is not implied by the supervenience principle, this principle does lend the Because Constraint some support. As mentioned above, this view on the matter seems to me plausible.
} 


\section{References}

Brandom, Robert (1994). Making it Explicit. Reasoning, Representing and Discoursive Commitment. Cambridge, Mass.: Harvard University Press.

Broome, John (2005). “Does Rationality Give Us Reasons?” Philosophical Issues 15: $321-37$.

Broome, John (2008). “Is Rationality Normative?” Disputatio 11: 153-71.

Davidson, Donald (1980). Essays on Actions and Events. Oxford: Oxford University Press.

Davidson, Donald (1984). Inquiries into Truth and Interpretation. Oxford: Oxford University Press.

Gibbard, Allan (2005). "Truth and Correct Belief." Philosophical Issues 15: $138-50$.

Glüer, Kathrin and Åsa Wikforss (2009). “Against Content Normativity.” Mind 118: $31-70$

Hare, Richard M. (1952) The Language of Morals. Oxford: Oxford University Press. Kolodny, Niko (2005). “Why Be Rational?" Mind 114: 509-63.

Kripke, Saul (1982). Wittgenstein on Rules and Private Language. Cambridge, Mass.: Harvard University Press.

Laurier, Daniel (2011). “Intentional Normativism Meets Normative Supervenience and the Because Constraint." Dialogue.

Millar, Alan (2004). Understanding People. Normativity and Rationalizing Explanation. Oxford: Oxford University Press.

Prior, Arthur (1960). "The Autonomy of Ethics.” Australasian Journal of Philosophy 28: 199-206.

Reisner, Andrew (2011). “Is There Reason to be Theoretically Rational?" In 
Reasons for Belief. Eds. Andrew Reisner and Asbjørn Steglich-Petersen.

Cambridge: Cambridge University Press.

Russell, Gillian (2010). “In Defence of Hume's Law”. In Hume, Is and Ought: New Essays. Ed. Charles Pigden. Hampshire: Palgrave MacMillan.

Schroeder, Timothy (2003). "Donald Davidson's Theory of Mind is Non-Normative." Philosophers' Imprint 3: 1-14.

Shah, Nishi (2003). “How Truth Governs Belief.” The Philosophical Review 112: 447-82.

Steglich-Petersen, Asbjørn (2006). "No Norm Needed: on the Aim of Belief." The Philosophical Quarterly 56: 499-516.

Steglich-Petersen, Asbjørn (2008). "Against Essential Normativity of the Mental.” Philosophical Studies 140: 263-83.

Steglich-Petersen, Asbjørn (2009). "Weighing the Aim of Belief." Philosophical Studies 145: 395-405.

Steglich-Petersen, Asbjørn (2011). "How to be a Teleologist about Epistemic Reasons.” In Reasons for Belief. Eds. Andrew Reisner and Asbjørn SteglichPetersen. Cambridge: Cambridge University Press.

Wedgwood, Ralph (2007). The Nature of Normativity. Oxford: Oxford University Press.

Wedgwood, Ralph (2009). “The Normativity of the Intentional.” In The Oxford Handbook of the Philosophy of Mind. Eds. Brian Mclaughlin and Ansgar 
Beckermann. Oxford: Oxford University Press.

Wittgenstein, Ludwig (1953). Philosophical Investigations. Oxford: Basil Blackwell.

Zangwill, Nick (2005a). “The Normativity of the Mental.” Philosophical Explorations 8: 1-20.

Zangwill, Nick (2005b). "Moral Epistemology and the Because Constraint.” In Contemporary Debates in Moral Theory. Ed. James Dreier. Oxford: Blackwell Publishers.

Zangwill, Nick (2010). “Normativity and the Metaphysics of Mind.” Australasian Journal of Philosophy 88: 21-39. 